\title{
Migración rural y pandemia: el rol del primer nivel de atención
}

\section{Rural migration and pandemic: role of the first level of care}

\author{
Lima, 24 de mayo del 2020.
}

Villena-Prado J J. Migración rural y pandemia: el rol del primer nivel de atención. Rev Soc Peru Med Interna. 2019;33(2): 89-90.

https://doi.org//0.36393/spmi.v33i2.529

\section{Sr. editor:}

En el mes de abril se hizo evidente uno de los tantos problemas sociales generados a causa de la pandemia, producto de la emergencia sanitaria y la paralización de actividades. Cientos de compatriotas se vieron con la dificultad de mantener sus puestos laborales, situación apremiante, en especial, para los que provienen de diferentes zonas del interior del país y dependen de los ingresos del día a día; es así que, el 14 de abril, se hizo noticia que un grupo de aproximadamente 700 personas, entre ancianos, adultos y niños, iniciaron su retorno hacia Huancavelica pues ya no tenían los medios para subsistir.

Similares situaciones se replicaron en los siguientes días teniendo como destino Apurímac, Ancash, San Martin, entre otras provincias, demandando de esta manera una pronta solución por parte del Gobierno. Este, en busca de una solución, promulgó la R.M. Nº97-2020-MINSA la cual brinda directrices sobre el traslado humanitario justamente con un enfoque en las personas que estén en un lugar distinto de su domicilio habitual y se encuentren en situación de vulnerabilidad, constituyendo una medida excepcional a la declaratoria de inmovilización social. ${ }^{(1)}$

Dentro de esta coyuntura, nos encontramos con la realidad de que la migración interna constituye actualmente un problema de salud pública puesto que la gran mayoría de los migrantes no cumple con las normativas estipuladas (por ejemplo, tener una prueba rápida negativa), ya sea por escasez de insumos o porque, simplemente, acuden por sus propios medios; de esta forma, se exponen al contagio durante el trayecto y a la posibilidad de nuevos contagios en otras provincias o distritos en los que aún no ha llegado la pandemia. Se debe tener en cuenta que por cada caso confirmado de COVID-19 hay probablemente entre 5 a 10 individuos con infecciones no documentadas. ${ }^{(2)}$

Con lo expuesto, se debe resaltar el rol principal que debe asumir el primer nivel de atención (PNA) ya que esel primer contacto con el paciente, la familia y la comunidad. La progresión de la pandemia debe generar la adaptación del PNA en torno a importantes funciones como la atención centrada en respuesta al COVID-19. De esta manera, se contribuye en la identificación de casos, contención de la expansión y manejo oportuno de todos los casos de manejo ambulatorio de COVID-19 en la comunidad; además, se propicia la descarga de la atención hospitalaria reforzando su capacidad resolutiva para absorber acciones que disminuyan la demanda de estos servicios. ${ }^{(3)}$

Por otro lado, se destaca su labor preventivo-promocional, mediante la difusión de medidas de saneamiento (higiene respiratoria, lavado de manos, distanciamiento social y el uso de mascarilla) para evitar más contagios y sensibilizar a la población a través de un trabajo multidisciplinario (médicos, licenciados en enfermería, psicólogos, etc.) sobre la importancia de realizar una cuarentena estricta de personas que provengan de lugares con trasmisión comunitaria. $^{(4)}$ Adicionalmente, se ha determinado la existencia de transmisión de la enfermedad en la fase pre sintomática; por lo tanto, se resalta la importancia del distanciamiento social en la respuesta de salud pública a la pandemia. ${ }^{(5)}$

Asimismo, se debe tener especial consideración y hacer seguimiento a las personas que pertenecen a grupos vulnerables por encontrarse con mayor riesgo a desarrollar casos moderados a severos; con énfasis en las enfermedades cardiovasculares, a la cabeza, hipertensión arterial. ${ }^{(6,7)}$ Para ello se puede hacer uso de nuevas herramientas como telemedicina y teleorientación para su correcto control y manejo, así como una intervención oportuna si fuese necesario.

Aproximadamente el $80 \%$ de los pacientes infectados tienen síntomas leves (tos, dolor de garganta y malestar general como síntomas principales) y alivian sin mayor tratamiento médico por lo que pueden ser abordados y manejados dentro del PNA. ${ }^{(8)}$ 
El 20 de mayo se aprobó la R.M. N 306-2020-MINSA con la cual se busca la adecuada organización de los servicios de salud, con énfasis en el primer nivel de atención, con la finalidad de reducir el impacto sanitario, social y económico frente a la pandemia por COVID-19. ${ }^{(9)}$

Finalmente, sabemos que las grandes crisis generan grandes oportunidades y la actual coyuntura no es ajena a ello. La pandemia ha revelado los graves problemas sanitarios que se venían arrastrando, ello nos obliga a replantear todo lo que creíamos correcto hasta la fecha. El personal de salud, en todos los niveles, viene batallando arduamente contra esta enfermedad; sin embargo, se debe dar énfasis al primer nivel de atención para lograr así un significativo descenso en la sobrecarga de atención hospitalaria, con un trabajo articulado desde este nivel.

\section{REFERENCIAS BIBLIOGRÁFICAS}

1. MINSA. Resolución Ministerial $N^{\circ} 097-2020$. Lineamientos para el traslado y cuarentena de personas que se encuentran fuera de su domicilio habitual, como efecto de las medidas de aislamiento social por la Emergencia Nacional por el COVID-19. 2020 abril. Disponible en https:/www.gob.pe/institucion/pcm/normas-legales/481860097-2020-pcm

2. Li R, Sen P, Bin Ch, Yimeng S, Tao Z, Wan Y, Jeffrey S. La infección sustancial no documentada facilita la rápida diseminación del nuevo coronavirus (SARS-CoV-2). Science. 2020;368, 489-493.

3. Nota Técnica. Adaptación del primer nivel de atención en el contexto de la pandemia covid-19: intervenciones, modalidades y ámbitos. OPS/OMS. Abril 2020 [citado 23 mayo 2020]. Recuperado a partir https:/www.paho.org/es/documentos/notatecnica-sobre-adaptacion-primer-nivel-atencion-contextopandemia-covid-19
4. Centro Nacional de Epidemiología, Prevención y Control de Enfermedades. Vigilancia, Prevención y Control de COVID-19. Distritos con alto riesgo de Transmisión por Departamento [Internet]. Perú: Ministerio de Salud; 2020 mayo. Disponible en: https://www. dge.gob.pe/portal/docs/tools/coronavirus/

5. Wei WE, Li Z, Chiew CJ, Yong SE, Toh MP, Lee VJ. Transmisión presintomática del SARS-CoV-2 - Singapur, del 23 de enero al 16 de marzo de 2020. MMWR. EPub: 1 de abril de 2020. DOI: http:/ dx.doi.org/10.15585/mmwr.mm6914e1

6. Brendan Mullen. ACC Clinical Bulletin COVID-19 Clinical Guidance for The Cardiovascular Care Team. American College of Cardiology. 6 de marzo del 2020, pag 1. Disponible en: https:// www.acc.org/ /media/Non-Clinical/Files-PDFs-Excel-MS-Wordetc/2020/02/S20028-ACC-Clinical-Bulletin-Coronavirus.pdf

7. Lei F, Karakiulakis G, Roth M. Are patients with hypertension and diabetes mellitus at increased risk for COVID-19 infection? The Lancet. 2020, vol 8 (4)

8. Centro Nacional de Epidemiología, Prevención y Control de Enfermedades. Vigilancia, Prevención y Control de COVID-19Alerta Epidemiológica $N^{\circ}$ 16[Internet]. Perú: Ministerio de Salud; 2020 mayo. Disponible en: https://www.dge.gob.pe/portal/docs/ alertas/2020/AE016.pdf

9. MINSA. Resolución Ministerial N³06-2020. “Norma Técnica de Salud para la Adecuación de la Organización de los Servicios de Salud con énfasis en el Primer Nivel de Atención de Salud frente a la pandemia por COVID-19 en el Perú". 2020 mayo. Disponible en https://www.gob.pe/institucion/minsa/normas-legales/581079-3062020-minsa

Jhonattan J.Villena-Prado, Dayana Y. Castillo-Roque

CORRESPONDENCIA:

jhonv1807@gmail.com

\footnotetext{
Médico general. Universidad Ricardo Palma. Centro de Salud Chungui I-3, La Mar, Ayacucho.
}

Médico general. Universidad Nacional Mayor de San Marcos. 